\title{
Anabases
}

ANABASES Traditions et réceptions de l'Antiquité

$17 \mid 2013$

Varia

\section{Pascal PAYEN, Les revers de la guerre en Grèce ancienne. Histoire et historiographie}

\section{Geneviève Hoffmann}

\section{OpenEdition}

\section{Journals}

Édition électronique

URL : http://journals.openedition.org/anabases/4292

DOI : 10.4000/anabases.4292

ISSN : 2256-9421

\section{Éditeur}

E.R.A.S.M.E.

\section{Édition imprimée}

Date de publication : 1 mars 2013

Pagination : 302-305

ISSN : 1774-4296

\section{Référence électronique}

Geneviève Hoffmann, «Pascal PAYEN, Les revers de la guerre en Grèce ancienne. Histoire et historiographie », Anabases [En ligne], 17 | 2013, mis en ligne le 01 avril 2013, consulté le 22 septembre 2020. URL http://journals.openedition.org/anabases/4292 ; DOI : https://doi.org/10.4000/anabases.4292

Ce document a été généré automatiquement le 22 septembre 2020.

(c) Anabases 


\title{
Pascal PAYEN, Les revers de la guerre en Grèce ancienne. Histoire et historiographie
}

\author{
Geneviève Hoffmann
}

\section{RÉFÉRENCE}

Pascal PAYEN, Les revers de la guerre en Grèce ancienne. Histoire et historiographie, Paris,

Belin, 2012, $445 \mathrm{p}$.

25 euros / ISBN 978-2-7011-4701-7.

La photographie choisie pour la couverture du livre de Pascal Payen (PP), publié chez Belin dans la collection "Antiquité au présent ", illustre une scène de l'Andromaque de Racine jouée le 3 mars 2008 au Théâtre du Pavé à Toulouse. Mère éplorée, victime de la folie des hommes, l'héroïne serre entre ses bras son fils menacé d'une mort prochaine. Par cette représentation qui traduit la conscience tragique des malheurs de la guerre et sa résonance dans la pensée occidentale est exposé le double enjeu de ces « revers de la guerre ». En effet, Pascal Payen, professeur d'histoire grecque à l'université de Toulouse, fondateur de l'équipe de recherche ÉRASME, poursuit et approfondit dans cet ouvrage la réflexion historique et historiographique qu'il mène depuis une dizaine d'années sur la place du phénomène guerrier dans les cités grecques. Dans son introduction (p. 7-24), il souligne l'originalité de son projet. Il n'a voulu ni écrire une nouvelle histoire de la guerre ni proposer une réflexion sur sa nature et ses fondements. Deux aspects ont retenu son attention : la face occultée des conflits et les polémiques qu'ils suscitent. En interrogeant la part censurée des affrontements, il entend restituer les souffrances des victimes et faire surgir un nouveau champ historique. Quant aux débats, dont les sources littéraires se font l'écho, ils prouvent que loin d'avoir vécu la guerre comme inévitable et belle, les Grecs l'ont perçue comme un échec. Ils n'ont cessé de la juger, de l'évaluer et de vouloir la mieux connaître pour en 
limiter les excès. L'auteur expose les difficultés de son entreprise. Les sources retenues pour sa recherche, maintes fois explorées, sont comprises dans le temps long de la réception, entre les dernières décennies $d u$ viII ${ }^{\mathrm{e}}$ siècle avant notre ère et le $\mathrm{II}^{\mathrm{e}}$ siècle de notre ère, quand des auteurs comme Plutarque, Pausanias, Arrien de Nicomédie donnaient aux Romains leur version de la guerre hoplitique. Pour interroger des allusions, voire des silences, PP a fait siennes les méthodes de la micro-histoire. De plus, l'étude du phénomène guerrier est renouvelée par une dimension historiographique mise en résonance avec les problématiques $\mathrm{du} \mathrm{xx}^{\mathrm{e}}$ siècle - des guerres mondiales à la décolonisation.

2 La première partie, intitulée "Sociétés guerrières ou sociétés en guerre ? (p. 27-86), élargit la réflexion conduite dans l'introduction. Dans le premier chapitre (p. 29-63), PP "soumet à la question" la documentation historique et historiographique dont il dispose pour interroger l'image traditionnelle de la cité hoplitique comme société guerrière. Il rappelle que les sources, tant littéraires qu'historiques et iconographiques, invitent à ne pas oublier « le reste » des conflits. Quant à la place centrale accordée à la guerre, elle répond toujours à un enjeu historique et historiographique. PP jette un pont entre le poète de l'Iliade et l'historiographie relative à la conquête d'Alexandre le Grand. Si l'épopée propose une réflexion sur « la misère de l'homme face à la contrainte de la guerre " (Simone Weil), les historiens modernes, spécialistes de la période hellénistique, ont imposé une conception de la politique suivie par Alexandre le Grand, conquérant ou civilisateur, en phase avec les problèmes militaires et politiques de leur temps, de l'Anglais George Grote à l'Allemand Gustav Friedrich Hertzberg. Au fil d'un riche parcours historiographique, PP relève dans son second chapitre (p.64-86) comment les études conduites depuis les années 1960 ont fait de la guerre un objet culturel. Il dégage les travaux pionniers qui vont dans le sens de sa démonstration - de l'analyse de la réforme clisthénienne à l'idéologie de la «belle mort " (Nicole Loraux). Au passage, il démontre que la guerre n'a jamais été un état permanent du monde grec.

Dans la deuxième partie intitulée: "Violences en guerre. Autopsie, morphologie, récit » (p. 87-178), les excès de la guerre sont inventoriés ainsi que les protections mises en place par les communautés civiques pour les juguler, les censurer ou les mettre à distance par la voix du poète tragique. Le chapitre III : « La suspension des usages et des lois» (p. 92-107), récapitule tous les principes qui font de la guerre « un univers de seuils et de limites» (p. 95) qui n'ont jamais été respectés. Dans le chapitre IV sur « la guerre censurée » (p. 108-131), les formes de violence sont décrites, qu'elles s'exercent sur le corps de l'hoplite à la fois "tueur et victime" ou sur les prisonniers des Latomies, sans oublier les captifs. Le chapitre V, «La guerre des non-combattants ", restitue à la tragédie grecque la place qu'elle doit occuper dans l'histoire des conflits (p.132-178), quand elle met en scène des captives ou qu'elle inspire le style des rhéteurs et des historiens affrontés au spectacle de l'horreur ordinaire sous forme de pillages, de massacres et de viols.

4 Les quatre chapitres qui composent la troisième partie : "Cités sur la défensive " (p. 181-262), soulignent la spécificité de la guerre grecque en abordant divers registres : le choix des armes (chapitre VI), le rôle des femmes (chapitre VII), la réflexion philosophique, principalement celle d'Aristote (chapitre VIII), et enfin le discours sur la défaite (chapitre IX).

5 Dans le chapitre VI (p. 184-215), l'aspect défensif de la guerre est mis en valeur par l'étude des assemblées des cités qui, contrairement aux assemblées homériques, 
favorisaient un véritable débat sur l'opportunité de déclarer la guerre. Quant à l'arme principale de l'hoplite, à savoir le bouclier, sa vocation est de défendre la cohésion de la phalange. Le chapitre VII (p. 216-231) cite les femmes à la barre du tribunal de l'Histoire pour relever "leurs interventions obliques" (p. 223) dans cette sphère où elles n'ont pas leur place selon l'idéologie dominante. Sous le titre "La guerre en lisière de la cité » (chapitre VIII, p. 232-246), PP démontre comment la communauté civique s'efforce de tenir la guerre à l'écart en se fondant sur quelques exemples pour étayer sa thèse. Le cas de la figure légendaire de la fameuse Praxithéa précède une analyse de la pensée aristotélicienne sur la place de la guerre dans la politeia. Enfin, les problèmes de la défaite, de son acceptation et de sa transcription littéraire font l'objet du chapitre IX (p. 247-262).

6 La quatrième partie, "La guerre à l'âge historiographique " (p. 265-332), invite le lecteur à une réflexion sur l'écriture de l'histoire militaire, d'Hérodote à Lucien. Le chapitre X: «Réprouver la guerre»(p. 268-293), propose une analyse rapide des traditions narratives de l'Orient ancien pour mieux souligner combien Hérodote, Thucydide et Xénophon sont originaux dans leur dénonciation de la guerre comme folie meurtrière. Dans le chapitre XI (p. 294-316), les œuvres des historiens et « l'agencement des faits » qui les fondent sont inscrits dans une tradition littéraire qui suppose convergence, confrontation et polémique. Aux trois historiens de l'époque classique sont ajoutés sous le titre ambigu de "variations » Polybe, Flavius Josèphe et Plutarque, parce qu'ils ont su regarder la guerre aussi du côté des vaincus. Enfin, le chapitre XII, qui porte le titre de la partie dont il est la conclusion, développe le thème de l'exil comme préalable indispensable à la pensée dite "historique » - d'Ulysse à Flavius Josèphe (p. 317-332).

7 La conclusion générale décline les apports de cet ouvrage en quelques pages (p. 333-336). Par son enquête, PP a reconstitué les souffrances subies par les résistants et les non-combattants, a précisé les limites assignées à la guerre, enfin a présenté la guerre comme « une institution contingente et contestable» (p. 336) et non comme un phénomène intangible et immobile. La dernière phrase de l'étude rappelle le propos principal : « Les Grecs ont peu à peu inventé et élaboré des modes de connaissance de la guerre qui sont aussi des ressources pour en assurer le contrôle » (p. 336).

Ce livre veut emporter la conviction. À une présentation didactique succèdent des analyses fouillées, et d'un chapitre à l'autre, l'idée qui fonde la thèse est répétée. Le lecteur ne risque pas de perdre de vue le but poursuivi. Les « revers » sont sans cesse redéfinis. Ils doivent s'imposer désormais comme une page de l'histoire des guerres grecques. Les notes très abondantes (p. 337-412), la bibliographie détaillée (p. 413-436) et l'index général (p.437-440) font de cet ouvrage bien structuré un instrument de travail indispensable à qui s'intéresse à l'historiographie de la guerre, à sa représentation comme à ses modalités.

9 Pétrie de références à bien des conflits, cette enquête est une lecture des guerres grecques au miroir de l'histoire contemporaine en retenant les méthodes de la microhistoire. D'une certaine manière, l'helléniste rend hommage aux historiens de la guerre de 14-18, il se situe dans leur sillage en cherchant à donner voix à l'indicible et à l'inaudible. Quoi qu'il en soit de ce choix épistémologique, le lecteur habitué à des études plus classiques risque d'être décontenancé par la composition des chapitres. Chaque thématique se nourrit en effet de sources qui appartiennent à des registres et à des époques différents. Dans le jeu de miroir entre les faits (ou les mythes) et 
l'historiographie qui les constitue, les repères semblent s'estomper, la chronologie disparaître.

La «cité » de Pascal Payen est principalement la cité athénienne, à moins qu'il ne s'agisse d'une cité rêvée, pétrie d'humanisme, héritière du "miracle grec ». Quand l'auteur écrit en conclusion: "La cité confie aux citoyens la charge d'une guerre défensive qui ne supprime pas la violence, mais qui peut en limiter la fréquence sinon l'intensité. La guerre de conquête n'est pas inscrite au programme politique de la cité grecque» (p.335), de quel moment historique parle-t-il ? Comment situer l'archè athénienne dans cette analyse? La cité de PP est une construction intellectuelle sans différences sociales ni conflits d'influences. Aristophane n'est jamais mentionné, sans doute parce qu'il ne peut pas nourrir la démonstration menée en faisant apparaître dans ses comédies une société divisée par des intérêts contradictoires. Les pages sur Hérodote, Thucydide et Xénophon sont particulièrement éclairantes car elles constituent une tradition littéraire que Pascal Payen maitrise parfaitement, mais pourquoi ne rien dire des sophistes qui ont contribué à forger la réflexion historique? Quant au tableau des captives dans l'épopée et à leur tragédie, peuvent-ils être une source documentaire comme une autre? De l'Iliade aux Troyennes d'Euripide, les souffrances des vaincus ne sont-elles pas un topos, un stratagème pour provoquer pitié et compassion? Les captives ont-elles pour objet principal de favoriser « une méditation sur la guerre et ses conséquences » (p.155) ou de provoquer cette secrète jouissance que suscite la description des malheurs des autres?

11 Ce livre complexe, dense et d'une érudition soutenue, ne manquera pas de susciter des débats prometteurs. Il n'est pas seulement un jalon dans l'historiographie des guerres grecques. Il renvoie aussi le lecteur à la nature problématique de la cité hoplitique en prouvant la spécificité du phénomène guerrier dans les mondes grecs. En définitive, et ce n'est pas son moindre mérite, il pose la question de l'écriture de l'histoire à l'aube du xxI ${ }^{e}$ siècle, par le mouvement même qui l'anime - des sources à l'historiographie.

\section{AUTEURS}

\section{GENEVIÈVE HOFFMANN}

Université de Picardie-Jules Verne

genevieve.hoffmann@wanadoo.fr 